\title{
A Interface do Mestrado Profissional em Educação com a Formação de Professores da Educação Básica
}

\author{
MARIA ELIZABETE SOUZA COUTO
}

Graduada em Pedagoga pela Federação das Escolas Superiores de Ilhéus e Itabuna/FESPI, Mestrado em Educação pela UFBA/UESC, Doutorado em Educação pela UFSCar/ São Paulo. Atua na Universidade Estadual de Santa Cruz/UESC, na pesquisa, ensino e extensão, nas áreas: formação de professores, alfabetização e prática pedagógica. E-mail: melizabetesc@gmail.com

\section{JEANES MARTINS LARCHERT}

Graduada em Pedagoga pela Universidade Estadual de Santa Cruz/UESC, Mestrado em Educação pela UFBA/UESC, Doutorado em Educação pela UFSCar/ São Paulo. Atua na Universidade Estadual de Santa Cruz/UESC, na pesquisa, ensino e extensão, nas áreas: currículo e educação e diversidade cultural. E-mail:jelarchert@yahoo.com.br 
Resumo: O presente artigo apresenta o Programa de Pós Graduação em Formação de Professores UESC -, e suas interfaces com a Educação Básica. Problematiza os processos formativos a partir das experiências vividas no cotidiano das práticas na docência e/ou na gestão. De natureza intervencionista a pesquisa desenvolvida nos projetos encaminha a formação do professor-pesquisador para a troca de experiências colaborativas, principalmente, no campo da educação infantil e da alfabetização. A integração do Programa com as escolas da Educação Básica tem proporcionado à Universidade pensar-se como debatedora das políticas públicas educacionais, comprometendo-se enquanto formadora de professores capazes de enfrentar problemas reais do processo educativo nas diversas atividades da educação dos municípios. Por fim, apresenta depoimentos dos egressos que colaboram para o entendimento da base teórico-metodológica da estrutura curricular e do rigor técnico-científico da formação.

Palavras-Chave: Professor-pesquisador. Educação Básica. Prática docente.

Resumen: En este artículo se presenta el Programa de Postgrado en Formación de Profesorado y sus interfaces con la educación básica. Analiza los procesos de formación de las experiencias de las prácticas de la vida cotidiana en la enseñanza y/o de gestión. Proyectos intervencionistas de investigación desarrollados en la formación de profesor - investigador para el intercambio de experiencias de colaboración, principalmente en el campo de la educación de la primera infancia y la alfabetización. La integración del programa con las escuelas de Educación Básica ha proporcionado la universidad de pensar como comentarista de las políticas educativas, comprometiéndose como la formación docente capaz de hacer frente a los problemas reales del proceso educativo en las diversas actividades de educación de los municipios. Finalmente, se presentan los testimonios de los graduados que contribuye a la comprensión del valor teórico - metodológico base del plan de estudios y el rigor técnico - formación científica.

Palabras Clave: Formación de profesores. La educación básica. la enseñanza de la práctica.

\section{A Interface do Mestrado Profissional em Educação com a Formação de Professores da Educação Básica}

\section{Introdução}

Os MPE dirigem o foco aos processos formativos e de investigação para o trato de problemáticas relativas ao ambiente profissional dos pós-graduandos e ao desenvolvimento de produtos que visem soluções e ou encaminhamentos e ou intervenções no âmbito das problemáticas apresentadas.

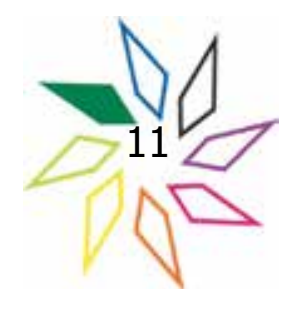


Nadia Fialho; Tânia Hetkowski, 2017

Este artigo tem como finalidade discutir e refletir sobre os desafios enfrentados na formação continuada de professores, considerando o contexto e as características de uma Universidade que atende a uma comunidade local e regional. Tais discussões iniciaram-se no momento da elaboração do projeto do Mestrado Profissional em Formação de Professores da Educação Básica - PPGE, da Universidade Estadual de Santa Cruz - UESC/BA, considerando a abrangência territorial da instituição e a distância a centros maiores para que os profissionais, principalmente aqueles que já estão desenvolvendo suas atividades na educação básica pudessem ampliar e aprofundar seus estudos e reflexões sobre a docência, a prática pedagógica, a gestão escolar e as políticas públicas, em nível de Pós Graduação. E, assim, começamos a nos perguntar: que formação será essa? Como estabelecer a relação entre a prática realizada na escola (gestão e docência) e a pesquisa? Os caminhos estão sendo construídos e apresentaremos em duas seções: O Mestrado Profissional em Formação de Professores da Educação Básica na UESC e a articulação entre o PPGE e a Educação Básica.

\section{Mestrado Profissional em Formação de Professores da Educação Básica na UESC}

Para a construção e efetivação da proposta do Mestrado, aprovado na reunião do CTC/ CAPES em novembro de 2012, com ênfase em processos de alfabetização e gestão de sistemas educacionais com o olhar para as necessidades da região Sul da Bahia, sua natureza tecnocientífica e sua dimensão social. No que diz respeito à especificidade da alfabetização e gestão educacional duas questões se sobressaem: o aprofundamento e a socialização das pesquisas dos professores, na Universidade, já em andamento, e, de outro, desafiá-los a refletir sobre novos enfoques teóricometodológicos, novos objetos, agregando, pela natureza do programa, ações interventivas e pontuais.

Em relação à natureza tecnocientífica, o desafio que se impõe é a construção da identidade do Programa, por estarmos apostando em uma modalidade de Pós Graduação, até então, iniciando no país; mas entendíamos que, se queríamos atender a professores da Educação Básica, fomentando melhores oportunidades formativas com o olhar para as situações reais da escola, docência, gestão etc., essa seria a proposta viável. 
Diante de tais realidades, essa proposta também estava relacionada com o compromisso e o papel social da UESC com a Região ${ }^{1}$. Assim, vem sendo por meio de desenvolvimento de novas práticas de aula e de materiais didáticos, bem como, com uma gestão compartilhada da educação com o avanço das novas tecnologias da informação que se poderá atingir a grande quantidade de profissionais do ensino básico. Para isto, o Programa foi pensado com o objetivo de

Compreender e colaborar com a gestão escolar no que se refere a formação do professor com vistas a qualidade da educação, as práticas pedagógicas e a implementação de políticas públicas da educação municipal (UESC, 2012).

Nesse sentido, o Programa foi organizado com duas linhas de pesquisa com ênfase em processos de alfabetização e gestão de sistemas educacionais, tendo como finalidade de promover

(...) a articulação integrada da formação profissional com entidades demandantes de naturezas diversas (redes de ensino estadual e municipais), visando melhorar a eficiência das organizações públicas e privadas por meio da solução de problemas, bem como gerar e aplicar processos de inovação apropriados (UESC, 2012).

O novo movimentou!!!... e este movimento exigiu um novo olhar 'para' os profissionais da Educação Básica na Região, visto que enxergaram, nessa oportunidade uma possibilidade para a ampliação da sua formação, o que proporcionou um movimento de natureza social, formativa e política.

No contexto atual, o Programa atende a profissionais dos diversos campos do saber ${ }^{2}$ que trabalham na Educação Básica nas redes municipal, estadual, federal e particular. Assim, para atender a esse movimento, foi necessária a construção de uma ação estratégica, política e educacional tendo como meta a indissociabilidade entre ensino, pesquisa e intervenção na universidade e na escola da educação básica.

O Programa está organizado em duas linhas de pesquisa: Alfabetização e Práticas Pedagógicas - que tem como finalidade aprofundar os "estudos sobre as abordagens teóricas e as práticas de alfabetização desenvolvidas na sala de aula e suas interfaces com a gestão da escola" (UESC, 2012); e Políticas Educacionais - que visa enfatizar os "estudos sobre a gestão escolar

1 A Universidade Estadual de Santa Cruz - UESC -, está situada na Região Sul da Bahia e fica entre as cidades de Itabuna e Ilhéus.

2 Estamos na quarta turma e recebemos mestrandos Pedagogia, Letras, Matemática, Geografia, Biologia, História etc. 
e sua relação com a qualidade da educação, práticas de implementação de políticas públicas e relação da instituição com a comunidade" (UESC, 2012).

Considerando a especificidade do Programa, que é atender a profissionais da Educação Básica; e, também, a natureza do Mestrado Profissional ${ }^{3}$, a relação entre teoria e prática e a articulação entre Universidade e Escola estão presentes, atendendo às suas propostas, nesse caso, enfatizando os processos formativos, a atitude investigativa relacionada ao ambiente profissional, ao desenvolvimento de produtos que contribuam a soluções, novos encaminhamentos e intervenções das problemáticas proposta (FIALHO; HETKOWSKI, 2017).

Dessa forma, as atividades práticas e de pesquisa estão presentes na estrutura do Programa e, por sua vez, nas disciplinas - momento em que os mestrandos desenvolvem situações de docência e gestão nas escolas, em especial, no próprio local que já atuam como possibilidade para refletir a sua prática e construir conhecimento $\mathrm{para} / \mathrm{na} / \mathrm{da}$ prática (GARCIA, 2009); com a finalidade, também, de subsidiar as reflexões relacionadas aos processos de pesquisa na docência e na gestão; bem como a integração de docentes e discentes do Programa à comunidade universitária e a Educação Básica. Algumas vezes, essas atividades, além de fazerem parte do planejamento de disciplinas, também contribuem à sistematização do Trabalho de Conclusão Final do Curso (TCFC).

Outro ponto que favorece o movimento das aprendizagens entre os professores credenciados no Programa e os mestrandos é a integração com a graduação/licenciatura que se realiza por meio de atividades de extensão que os estudantes participam desde a organização a participação de palestras e projetos de intervenção social, especialmente, nas áreas da Alfabetização, Educação Infantil e Políticas Educacionais. Situações que favorecem a ampliação de um conhecimento importante sobre o funcionamento da universidade, os processos de produção e divulgação do conhecimento por meio da extensão. Ao participarem dos grupos de estudos e pesquisa têm a

3 Art. $3^{\circ} \mathrm{O}$ Mestrado Profissional é definido como modalidade de formação pós-graduada stricto sensu que possibilita: I- a capacitação de pessoal para a prática profissional avançada e transformadora de procedimentos e processos aplicados, por meio da incorporação do método científico, habilitando o profissional para atuar em atividades técnico-científicas e de inovação; II- a formação de profissionais qualificados pela apropriação e aplicação do conhecimento embasado no rigor metodológico e nos fundamentos científicos; III- a incorporação e atualização permanentes dos avanços da ciência e das tecnologias, bem como a capacitação para aplicar os mesmos, tendo como foco a gestão, a produção técnico-científica na pesquisa aplicada e a proposição de inovações e aperfeiçoamentos tecnológicos para a solução de problemas específicos. (CAPES, Portaria Normativa N 17, 2009). 
oportunidade de acompanhar o debate crítico sobre a produção do conhecimento por meio da pesquisa.

A graduação/licenciatura também é convidada, por intermédio dos colegiados dos cursos de Licenciaturas, a participar como ouvinte dos Seminários Internos de Pesquisa - SIP, no Programa. Os Seminários reúnem os diversos trabalhos de pesquisa e com a participação das docentes e mestrandos construímos um momento de discussão, reflexão de natureza teórica, metodológica e prática, bem como de colaboração com as pesquisas.

Os mestrandos vêm participando de eventos organizado na Instituição, na área de Educação, como pareceristas, coordenando mesas, comunicações e apresentando trabalhos resultado dos estudos e pesquisa; bem como participando de curso que são organizados para professores da Educação Básica, projetos de pesquisa e extensão na área de Políticas Públicas e Educação Infantil. Esses indicadores têm oportunizado uma troca de conhecimentos e experiências, bem como a integração com a graduação e a educação básica.

Além dessas ações, as disciplinas desenvolvem oficinas, ministradas pelos mestrandos com temáticas que favorecem a ampliação da formação de professores, num movimento dialético, no qual os mestrandos e alunos da graduação/licenciaturas estão em formação numa visão de processo, com um movimento de permanente 'vir a ser', como o movimento das ondas que se desdobram em ações que se dobram e concretizam em processo de reflexão (MORAES, 1996) e em nova configuração formativa.

Com a finalidade de estabelecer a articulação entre Pós Graduação (mestrandos que são professores da Educação Básica) e Graduação (futuros professores) por meio da troca de saberes e fazeres, foi que nasceu a proposta das oficinas com temáticas relacionadas à Alfabetização. Estas aconteceram em dois momentos diferentes: o primeiro, com os alunos do curso de Pedagogia que é ofertado por meio do PARFOR ${ }^{4}$ na própria Universidade; o segundo com os alunos do curso de Pedagogia, ofertado pela $\mathrm{UAB}^{5} / \mathrm{EAD}$.

4 Plano Nacional de Formação de Professores da Educação Básica (PARFOR) atende a professores das redes públicas de estados, municípios e do Distrito Federal, que não possuem curso superior ou que lecionam em área diferente da sua formação.

5 Universidade Abeta do Brasil (UAB/EAD) em cinco polos de apoio presencial: Ilhéus, Itabuna, Ibicuí, Amargosa e Teixeira de Freitas. 
A proposta da oficina era refletir sobre as práticas investigativas na alfabetização e os conhecimentos necessários para o ensino na alfabetização, considerando o momento da aquisição do Sistema de Escrita Alfabética (SEA).

Assim, uma prática investigativa requer o ato de investigar que, para Ponte, Brocardo e Oliveira (2006), busca conhecer/aprender o que ainda não se sabe, fazendo relações entre os conteúdos conhecidos ou desconhecidos, procurando identificar suas propriedades e o processo de resolução. Este ato, conforme os autores, segue passos definidos: 1)identificação do problema a resolver, a descoberta preliminar e a formulação de novas questões;2) levantamento de hipóteses; 3)realização de atividades e reformulação das hipóteses;4)organização de novos questionamentos e argumentos, para refletir sobre a resposta encontrada. E, por fim, a ação de aprender por meio da investigação, aprender o conteúdo, os "processos de aprender sobre como ensinar e de aprender sobre como ser professor (KNOWLES; COLE; PRESSWOOD, 1994) e, também, aprender a ser pesquisador na escola.

\section{A articulação entre o PPGE e a Educação Básica}

O Programa Mestrado Profissional em Formação de Professores da Educação Básica se insere na, para e com a Educação Básica, sendo esta forma e conteúdo, meio e conhecimento, face e interface. As interfaces são planejadas e efetivadas em todas as atividades dos componentes curriculares, a educação escolar é contextualizada com a finalidade de reflexão e análise dos problemas inerentes à realidade educacional e social da Educação Básica, igualmente é potencializada a formação do professor, na abordagem do professor - pesquisador proporcionando aos mestrandos uma formação que promova a reflexão do professor como formador e gestor das ações na escola.

Diante das estratégias de ações que estão sendo desenvolvidas, notamos que estamos proporcionando ao mestrando condições de formar-se, sendo formado e estando em formação. Tudo começa em sala de aula do Mestrado, e concretiza na sala de aula da escola - desde a realização do planejamento quando as docentes, juntamente, com os mestrandos refletem sobre o processo de alfabetização, educação infantil, políticas públicas, gestão etc. e as possibilidades e necessidades formativas do futuro professor, considerando que "pesquisar e ensinar são atividades distintas e dependem de diferentes tipos de conhecimentos, habilidades e disposições" (SANTOS, 2001,p. 15), enfatizando a necessidade de tornar os alunos-mestres consumidores críticos 
das pesquisas produzidas no campo educacional, bem como participantes de projetos de pesquisa (ZEICNHER, 1993) na Escola e na Universidade, com condições de ser questionador, investigador, reflexivo e crítico.

Em relação às oficinas, o lugar de ser formador 'mexeu' com as concepções dos mestrandos, visto que, ainda, não tinha pensado em tal possibilidade. E, assim, refletiram: "temos formação para dar aula, mas não temos formação para formadores" (Depoimento de um mestrando, 2015).

O que é ser formador? Tal indagação indica que para a natureza do Programa era preciso essa reflexão. Começamos a pensar em formação que promovesse o desenvolvimento profissional dos mestrandos. Inicialmente, vendo na formação um “(...) elemento importante de desenvolvimento profissional, mas não é o único e talvez não seja o decisivo” (IMBERNÓN, 2012, p. 97), visto que, algumas vezes, a formação aconteceu, mas o desenvolvimento profissional não contribuiu para a melhoria do ensino e da aprendizagem. Nesse sentido, a formação contribui quando proporciona o “(...) desenvolvimento profissional do professorado no âmbito trabalhista e de melhoria das aprendizagens profissionais no contexto específico em que se trabalha, já que ajudará a melhorar o ensino e a aprendizagem do alunado, que constitui o objetivo fundamental da docência (...)" (IMBERNÓN, 2012, p. 98). Entretanto,

(...) é um processo que se desenvolve no conjunto, com os colegas, com os gestores, com os alunos e com a comunidade, exigindo uma reconceitualização de conceitos no campo teórico, prático, metodológico e na socialização das experiências (COUTO; GONÇALVES, 2015, p. 153).

Para André (2016, p. 31), o desenvolvimento profissional,

(...) "é um processo que deve incluir todos os envolvidos na tarefa de educar, principalmente na educação escolar. (...) deve envolver todo o coletivo da escola, não apenas o professor, (...) todos devem ter oportunidade de se desenvolver profissionalmente".

E, assim, pensamos na formação dos mestrandos, principalmente, quando no início das atividades perguntamos: 'quem sou eu, profissional, antes de ingressar no Programa?'; e, já deixa uma reflexão para o final: 'o que este Mestrado contribuiu para a minha formação profissional?' É um movimento constante, de ação, reflexão, ação (SCHÖN, 1992). Não se trata apenas de uma formação para docência e gestão, mas o que Giroux (1997) chamou de formação intelectual do professor para transformar pessoas e situações (SILVA, 2005). 
Nesse contexto, ser formador é estar imerso nas ações do cotidiano da escola (UniversidadeEscola), aprendendo, ensinado e se formando, constantemente. Isso é, o formador, ao vivenciar os processos de aprendizagem da docência e da gestão, está proporcionando condições para seu próprio desenvolvimento profissional - embora a formação do formador ainda é um processo com poucas reflexões e publicações, ainda não muito explorado nas pesquisas (VAILLANT; GARCIA, 2001).

Vaillant indica características que são inerentes ao formador de professores, tais como,

(...) aperfeiçoar os conhecimentos e habilidades dos professores mal capacitados; fornecer conhecimentos especializados em matérias que se diagnosticam claras deficiências; facilitar a introdução de reformas educativas, de inovações ao currículo e de novas técnicas ou novos textos de estudo (VAILLANT, 2003, p. 10-11).

Ser formador é, então, um “(...) território pouco explicado e menos explorado” (VAILLANT, 2003, p. 28) em contextos e "mundos sociais" (SISKIM, 1994 apud BOLIVAR, 2005, p. 28) diferentes, visto que recebemos, no Programa, profissionais da Educação de várias cidades do sul e extremo sul da Bahia.

$\mathrm{Na}$ proposição de formar-se, formando, a proposta do Programa vem sendo concretizada, tendo como meta o desenvolvimento de uma "atitude investigativa" (SANTOS, 2001, p. 24) (grifo da autora) que valorize a troca de experiências, a utilização de recursos diversificados para encontrar soluções que ajudem a responder, explicar, esclarecer os desafios da prática docente e da gestão, ou seja,

(...) formação profissional capaz de não apenas atuar com competência em sala de aula, mas também para a formação de um profissional capaz de reconhecer as relações existentes entre seu trabalho, as políticas públicas na área educacional e as complexas relações existentes entre sua atividade profissional e a realidade sociocultural na qual esta se insere (SANTOS, 2001, p. 24).

Essa atitude investigativa vem sendo uma aprendizagem constante para todos - professores e mestrandos - visto que, no primeiro momento, ao conhecer os nossos mestrandos, notamos que têm experiência na docência e na gestão, mas a pesquisa ainda não faz parte do cotidiano da profissão. Ainda era uma tarefa da Universidade e não da Escola. Para desenvolver essa atitude exige aprendizagens para a busca de dados, tais como: 
Cabe aos formadores ensinar a localizar fontes de consulta, examiná-las, processá-las. Quais informações podem dar suporte ao problema? Onde devem ser buscadas? Como tratá-las? Como distinguir entre o que é relevante e o que pode ser descartado? Essas são as perguntas fundamentais que todo pesquisador precisa (ANDRÉ, 2016, p. 23).

Essa foi uma realidade, mas o movimento de aprender, refletir e socializar os trabalhos a partir de situações da prática vem ajudando-nos a avançar e compreender o lugar da pesquisa na Escola, bem como rever os conhecimentos construídos para/da/na prática (GARCIA, 2009). Uma aprendizagem que requer uma mudança de paradigma, desde o 'olhar' a escola, o aluno, o conhecimento, o professor, o gestor, a avaliação, os processos de ensinar e aprender e ser profissional.

Nessa direção, para Garcia (2009), o conhecimento para a prática pode ser entendido considerando que a relação entre conhecimento e prática é aquela na qual o conhecimento serve para organizar a prática e, desta forma, conhecer mais (conteúdos, teorias educativas, estratégias instrucionais) para o desenvolvimento de uma prática mais eficaz. O conhecimento para ensinar é um conhecimento formal, que deriva da pesquisa universitária. Nesta perspectiva, a prática tem relação com a aplicação do conhecimento formal às situações práticas de ensino.

Já o conhecimento na prática enfatiza,

(...) "a investigação sobre aprender a ensinar tem sido colocada na procura do conhecimento na ação. Pensa-se que aquilo que os professores conhecem está implícito na prática, na reflexão sobre a prática e na indagação e narrativa dessa prática" (GARCIA, 2009, p. 17).

Tal perspectiva indica uma concepção de que o ensino é uma atividade que envolve incerteza, espontaneidade, contextualização e construção como resposta às especificidades e diversidades do dia a dia das escolas e salas de aula. O conhecimento emerge da ação, das tomadas de decisões que os professores tomam. É "um conhecimento que se adquire através da experiência e deliberação, sendo que os professores aprendem quando têm a oportunidade de reflectir sobre o que fazem" (GARCIA, 2009, p. 18).

E o conhecimento $d a$ prática pode ser compreendido numa perspectiva da investigação qualitativa, aproximando-se do movimento chamado 
(...) 'o professor como investigador'. Parte-se da ideia que em ensino não tem sentido distinguir entre conhecimento formal e prático, mas que o conhecimento é construído de forma colectiva no interior de comunidades locais, formadas por professores que trabalham em projectos de desenvolvimento da escola, de formação ou de indagação colaborativa (COCHRAN -SMITH; LYTLE, 1999, apud GARCIA, 2009, p. 18) (grifo do autor).

O PPGE, por meio das ações desenvolvidas até momento, vem planejando ações que contribuam para que mestres, mestrandos e professores possam construir esse percurso de elaboração de conhecimento em colaboração e, assim, compreender em que 'lugar' e 'tempo' está trabalhando com uma formação que enfatize o conhecimento para/na/da prática.

Diante de tais reflexões, apresentamos depoimentos de egressos indicando a caminhada que estamos traçando na continuidade da formação de professores da Educação Básica:

Repensar minha prática pedagógica, meu objeto de ensino, a possibilidade do ensino da escrita nas aulas de espanhol e, acima de tudo, que ainda podemos vislumbrar a educação como o caminho de mudança (Egresso).

Os estudos durante o mestrado trouxeram grandes contribuições para a minha atividade profissional, especificamente as pesquisas de campo realizadas nas disciplinas de Princípios e Práticas Investigativas em Alfabetização; Gestão Pedagógica na Educação Matemática e Prática de Pesquisa 3 e 4 (Egresso).

O Mestrado proporcionou-me uma visão mais ampla sobre a educação, ampliou os conhecimentos sobre as políticas públicas educacionais e isso permitiu-me atuar de forma mais consciente e responsável (Egresso).

Aprendizagem significativa, abertura de horizontes, aprimoramento dos conhecimentos, ampliação da verdadeira situação da educação no Brasil, valorização do educador, principalmente do alfabetizador e da importância da pesquisa na educação (Egresso).

Atitude mais crítica e reflexiva diante das questões educacionais e estímulo à auto formação (Egresso).

[...] a construção do conhecimento [que] está interligado com a função docente (Egresso). 
Mais aprofundamento teórico, devido aos estudos, leituras e produções textuais e participação em seminários, simpósios e congressos na área de Formação de Professores (Egresso).

Estes depoimentos direcionam nosso olhar para a efetivação de um programa que vem estabelecendo o que Anderson e Herr (1999) chamam de

\begin{abstract}
'aliança produtiva', com a finalidade de fortalecer áreas comuns e possibilidade de colaboração entre as duas culturas - da universidade e escola, dos professorespesquisadores, professores da educação básica e [mestrandos, mestres] sem marginalizar novas epistemologias. É nessa interlocução que os autores sugerem as alianças produtivas como campo colaborativo de aprendizagens entre os sujeitos no espaço da escola na universidade, considerando a reconceitualização da pesquisa do professor, sem se descuidar dos critérios e da validação da pesquisa, construindo e desenvolvendo, assim a comunidade de aprendizagem de professores. (LÜDKE, 2001, apud MORORÓ; COUTO, 2013, p. 206) (grifo das autoras).
\end{abstract}

Assim, as ações que estão sendo realizadas (oficinas, cursos, palestras, eventos etc.) além de constituir-se nessa aliança produtiva (LÜDKE, 2001), contribuem para a construção de uma atitude investigativa (SANTOS, 2001) para o desenvolvimento de práticas investigativas (PONTE; BROCARDO; OLIVEIRA, 2006) e uma reflexão sobre o formador na escola e na universidade (VAILLANT, 2003).

Tais ações favorecem a integração com a sociedade e o mercado de trabalho - Escola, Secretaria de Educação dos municípios e estado -, visto que fomentam pesquisas intervenção e pesquisa-ação que vêm sendo desenvolvidas com a natureza técnico-científica e viabilizando o retorno (produto final) à comunidade educacional e uma contribuição para análise, reflexão e avanço nas políticas educacionais locais vigentes. Essa integração proporciona a universidade pensar-se como debatedora das políticas públicas na e para a educação, comprometendo-se enquanto formadora de profissionais que atuam as diversas atividades da educação nos municípios.

Para finalizar, recorremos às reflexões de Lessard (2006, p. 12) que, escrevendo sobre a Universidade e a formação profissional dos docentes, traz perguntas para reflexão, e uma delas, também, vale para o nosso contexto:

Como formar docentes aptos a aprenderem a partir de sua prática, sendo esta submetida a prescrições abertas? Nesse caso, a entrada privilegiada não é a 
dos saberes, nem mesmo das tarefas; é a do sujeito confrontado com situações profissionais complexas e parcialmente indeterminadas.

Com base nessas ideias e reflexões é que o PPGE vem construindo, na coletividade, uma proposta de formação que se propõe a uma análise do contexto da escola, da gestão e da docência como um campo aberto de soluções, visto que as respostas de hoje nem sempre darão conta para solucionar os problemas de amanhã, principalmente, pela sua abrangência territorial e da formação dos próprios profissionais.

\section{REFERÊNCIAS}

ANDERSON, G.; HERR, K. The New paradigma wars: is there room for rigorous practitioner knowledge in schools and universities? In: Educational Researcher. v. 28, n. 5, p. 12-40, jun/jul, 1999.

ANDRÉ, MARLI. Formar o professor pesquisador para um novo desenvolvimento profissional. In: ANDRÉ, MARLI (Org.). Práticas inovadoras na formação de professores. São Paulo: Papirus, 2016.

BOLIVAR, A. Conocimiento didáctico del contenido y didácticas específicas. Revista de currículum y formácion del profesorado. v. 9, n. 2, p. 01-39 Granada, 2005.

BRASIL. Portaria Normativa, N 17. CAPES, 2009.

COUTO, M. E. S; GONÇALVES, A. L. A formação dos formadores: um estudo sobre o PNAIC. In: Práxis Educativa, Ponta Grossa, v. 11, n. 1, p. 151-170, jan./abr. 2016 Disponível em: http://www.revistas2.uepg.br/index.php/praxiseducativa Acesso em 03.03.2017.

FILAHO, N. H.; HETKOWSKI, T. M; Mestrados Profissionais em Educação: novas perspectivas da Pós Graduação no cenário brasileiro. In: Educar em Revista. $n^{\circ} 63$, jan/mar. Curitiba, 2017.

GARCIA, C. M. Desenvolvimento profissional docente: passado e futuro. In: Sísifo / Revista de Ciências da Educação. Nº 8, jan/abr, 2009. 
IMBERNÓN, F. Inovar o ensino e a aprendizagem na universidade. Tradução de Silvana Cobucci Leite. São Paulo: Cortez, 2012.

KNOWLES, J. G.; COLE, A. L.; PRESSWOOD, C. S. Through preservice teachers' eyes: experiences through narrative and inquiry. New York: McMillan College Publishing Co, 1994.

LESSARD, C. A universidade e a formação profissional dos docentes: novos questionamentos. In: Educação \& Sociedade. v. 27, n. 94, jan/abr. Campinas, 2006.

MORAES, M. C. O paradigma educacional emergente: implicações na formação do professor e nas práticas pedagógicas. In: Em Aberto. Ano 16, nº. 70, abr/jun, 1996.

MORORÓ, L. P.; COUTO, M. E. S. A construção do conhecimento profissional docente. In: EUGÊNIO, B. G.; SANT’ANA, C. de c.; COSTA, J.S (Orgs.). Políticas Educacionais, Práticas Pedagógicas e Formação. Campinas: Alínea, 2013.

PONTE, J. P.; BROCARDO, J. OLIVEIRA, H. Investigações matemáticas na sala de aula. Belo Horizonte: Autêntica, 2006.

SANTOS, L. C. P. Dilemas e perspectivas na relação entre ensino e pesquisa. In: ANDRÉ, MARLI (Org.). O papel da pesquisa na formação e na prática dos professores. São Paulo: Papirus, 2001.

SCHÖN, D. Formar professores como profissionais reflexivos. In: NÓVOA, A. Os professores e sua formação. Lisboa: Dom Quixote, 1992.

SILVA, T. T. da. Documentos de identidade. Uma introdução às teorias do currículo. 2. ed. Belo Horizonte: Autêntica, 2005.

UESC. Projeto do Programa de Pós Graduação em Formação de Professores, Universidade Estadual de Santa Cruz. Ilhéus-Bahia, 2012.

VAILLANT, D. Formação de professores: estado da prática. Rio de Janeiro: Programa de Promoção da Reforma Educativa na América Latina e Caribe, 2003. (Série PREAL Documentos, $n$. 25).

VAILLANT, D.; GARCIA, C. M. Las tareas del formador. Málaga: Ediciones Aljibe, 2001

ZEICHNER, K. M. A formação reflexiva de professores: ideias e práticas. Lisboa: Educa, 1993. 